\title{
Perception and Practices of Female Sex Workers towards Sexually Transmitted Infections in Greater Cairo, Egypt
}

\author{
Omar O. Zidan', Hany O. Abo Alwafa ${ }^{2}$ and Waled A. Ayad ${ }^{3}$ \\ ${ }^{1}$ Public Health and Community Medicine Department, ${ }^{2}$ Dermatology and Andrology \\ department, ${ }^{3}$ Obstetrics \& Gynecology department Damietta Faculty of Medicine, AL- \\ Azhar University, \\ Received: April 2016 Accepted: June 2016
}

\begin{abstract}
Objective: to study the perception and practices of sexually transmitted infections among female sex workers in Greater Cairo. Methods: A cross sectional study including 431 of female sex workers. Results: $77.3 \%$ of participants knew about STIs. The majority (70.3\%) claimed refusing sex in presence of STIs. However, unusual vaginal discharge last year was reported by $76.1 \%$ of participants, and genital ulcers by $15.5 \%$. Only $40.1 \%$ informed their partners if having STIs and $63.1 \%$ claimed immediately starting treatment either from private or governmental facilities $(45.9 \%$ and $33.6 \%$, respectively). AIDS was known by $92.8 \%$ of participants while only $9.3 \%$ ever attended a raising awareness session. Correct methods of infection were known by $64.3 \%$ for breast milk, $78.4 \%$ from mother to her baby and $76.3 \%$ for sharing needles. Having one faithful partner, abstain from sex and proper use of condoms were the main preventive measures reported by participants $(54.8 \%, 54.8 \%$ and $40.4 \%$, respectively). Only $31.3 \%$ accepted taking care of an infected friend. Confidential counseling and testing for HIV was known by $57.1 \%$ but only $8.4 \%$ performed the test. Conclusion: The majorities of participants were knowledgeable about STIs and still had some misconceptions and a negative attitude towards people living with HIV. Key message: The paper addresses an issue for which limited information is available in our region due to illegal pattern of sex working. In many low prevalence countries the HIV epidemic is usually fueled by spread in most at risk population as sex workers before it turns to a generalized epidemic. The perception of HIV and STIs risk among sex workers is important to stimulate them to adopt harm reduction policies which can protect them and community from STIs including HIV infection.
\end{abstract}

Keywords: Female sex workers, AIDS, Sexually transmitted infection.

Corresponding author: Omar Omar Zidan Email: dr.zedan77@yahoo.com. Tel.: +201028116650

\section{Introduction}

The practice of commercial sex is something identified in all societies throughout history. According to the report by the Joint United Nations Program on HIV-AIDS (UNAIDS) there are approximately 35.3 million people infected with HIV worldwide. This report emphasized that female sex workers (FSWs) are one of the groups at the greatest risk of acquiring and transmitting sexually transmitted infections (STIs) and human immune- 
deficiency virus (HIV). ${ }^{1}$ The World Health Organization (WHO) reported that sexual transmission is responsible for over $75 \%$ of new HIV infections occurring globally. The WHO report highlighted that FSWs and their clients had a higher risk of contracting STIs/HIV. This is due to the extensive number of sexual encounters and to the factors directly or indirectly related to commercial sex situations. The WHO report also stated that FSWs who work illegally are the population group most susceptible to this infections. ${ }^{2}$ Nevertheless, there is also evidence suggesting that debt dependency, low pay and poor living conditions may jeopardize the health and safety of FSWs. It was reported that when FSWs have control over their own working situation and insist on safer sex relations, the risk of and vulnerability to STIs/HIV could be significantly reduced. ${ }^{3}$ Risk perceptions is a complex multifactorial process built on the experiences that a person undergoes during the course of his or her life which are directly or indirectly influenced by socioeconomic, political and cultural contexts. ${ }^{4}$ Worldwide female sex workers are considered a risk group for heterosexual spread of immunodeficiency virus. ${ }^{5}$ Sexually active young persons are the main sector in the communities affected by sexually infectious diseases including HIV. STIs and HIV and its complications ranks in the top five disease categories for which adult seek health care in developing countries. ${ }^{6}$ Causes behind elevated rates of STIs and HIV are complex. The main reasons include biological factors, risky sexual behavior pattern, transmission dynamics and treatment seeking behavior. ${ }^{7}$ Comprehensive and correct knowledge about STIs including HIV among both young men and young women has increased slightly since 2008 but still there is effort to be done to improve knowledge and behavior. ${ }^{8}$ Extensive levels of misconceptions and misinformation regard HIV/AIDS are present in Middle East and North Africa ${ }^{9}$ Sexually transmitted infections (STIs) can be markedly reduced by having correct knowledge about methods of transmission and prevention of HIV, regular and correct use of condom as important tool for any successful STIs/AIDS control program.

\section{Materials and methods:}

Study setting: A cross-sectional study was conducted in Greater Cairo that includes three Governorates namely, Cairo, Giza and Qualiobia. These governorates accommodate a population of nearly 18.5 millions according to latest census data. ${ }^{10}$

Sample size and sampling technique: Target population was FSWs representing different categories as identified by focus group discussions (FGDs) with FSWs. Results of FGDs identified the different categories of FSWs and the main places of their gathering. Information gained from AlShehab Non -Governmental Organization working with sex workers validated the same information. Main categories of FSWs working in Greater Cairo were Streets, Bars and night clubs, Dancers, Brothels, Coffee shops and discotheques and Hotels.

Sample size was determined to be 384 based on estimated level of knowledge ranging between $50-55 \%$ of ideal with $95 \%$ confidence limit and $80 \%$ power of the study. The sample size was increases to 431 to increase validity of results and compensate for non response. Researchers prepared a list of places 
where sex workers tended to gather based on information gained form FGDs and categorized by the different identified categories of sex workers. For each category, the suitable timing for visiting the gathering place was identified to ensure cooperation of the study subjects and avoid interfering with their work needs.

A time location sampling technique was used for data collections. One place for each category was randomly selected and all available sex workers at the time and place were interviewed by data collectors. The process was repeated and another set of places were randomly chosen and visited until the desired sample size was obtained. The researchers did not succeed to get approval from hotel managers to conduct fieldwork there, so sex workers at hotels were not included in the study. In addition, brothel based sex workers were not included due to lack of safety for data collectors during the interviews.

Data collection methods and tools: A questionnaire sheet was used to study the behaviors of FSWs. This questionnaire was adapted from the questionnaire published by family health international. ${ }^{11}$ Necessary modifications were made to make it suitable for the situation of sex work in Egypt. The questionnaire sheet included questions covering background characteristics, Marriage, family and work, sexual history: Age in years of first time selling sex, duration of sex work in years, Information about paid/unpaid sexual partners.

A pilot study was conducted in order to test the questionnaire to ensure its suitability for data collection. Data collection was performed through direct interviews with study subjects by trained interviewers from Al-Shehab
Organization, which had long experience working with sex workers on different issues related to prevention of HIV infection and providing social and legal support.

The collected data were organized, tabulated and analyzed using SPSS (Statistical package for social studies) version 21 (IBM Inc., Chicago, Illinois, USA). For quantitative variable, the mean and standard deviation were calculated. For categorical variable, the number and percentage were calculated.

Ethical considerations: Data collection was anonymous. Confidentiality was ensured during the whole study period where no data were linked to names or specific persons. No pressure of any kind was used for recruitment of the study subjects. Witnessed verbal consent was taken before the interview. The data collectors explained the study objectives and content of the questionnaire before starting data collection. The ethical permission for the study was taken form Ministry of Health and IRB of Tanta Faculty of Medicine.

\section{Results:}

The total number of studied sex workers was 431 . Out of them $52.7 \%$ were less than 30 years of age with a mean age of $29.38 \pm 9.48$ and a median age of 27 years. Those who attended schools represented $60.8 \%$. Nearly one half $(49.2 \%)$ had completed primary education while only $19.1 \%$ completed university education with a mean of $10.18 \pm 3.24$ years of education. Those who ever or were currently married during the study period represented $65.9 \%$. Living accommodation was with family among $41.3 \%$ followed by living with husband (36.7\%). Those who depended solely on sex work for living represented $39.9 \%$. On the other hand, $53.8 \%$ reported 
having other jobs. Nearly $40 \%$ admitted alcohol intake, which was reported to be daily by $7 \%$ and occasionally by $32.9 \%$. Drug intake was reported by $49 \%$ which was mostly hashish $(96.2 \%)$ and $37.6 \%$ of drug intake was reported to be associated with sexual practices. Drug injection was reported by $5.6 \%$ during last year. (Table1)

STIs were known as a group of diseases by $77.3 \%$ of study subjects. Bad odour vaginal discharge $(83.1 \%)$ and unusual vaginal discharge $(75.9 \%)$ were recognized as STIs manifestations followed by genital itching (71.7\%), genital ulcers $(45.0 \%)$ and burning sensation during urination (41.3\%). Manifestations of STIs among men were reported as urethral discharge (74.2\%), genital itching $(63.1 \%)$, and burning sensation during urination $(48.3 \%)$ and genital ulcers $(45.7 \%)$. The main action taken by sex workers with a client suffering from STIs was refusal sex (70.3\%). On the other hand, $17.4 \%$ reported practicing sex with infected partner without using condoms. Sex workers who suffered from unusual vaginal discharge last year represented $76.1 \%$ and $15.5 \%$ suffered from genital ulcers. Infected sex workers used to inform partner about being suffering from STIs as reported by $40.1 \%$ while $42.5 \%$ never did. Those who stopped working until taking appropriate treatment represented $35.3 \%$ while $13.9 \%$ reported continuing working without using condom. Infected sex workers with STIs usually start treatment after few days of manifestations $(63.1 \%)$ while $14.8 \%$ were never interested in getting treatment. The preferred source for STIs treatment was private clinics or hospitals as reported by $45.9 \%$ followed by governmental hospitals (33.6\%) and pharmacies (20.9\%) (Table 2).

A high percentage of participants $(92.8 \%)$ had some information about HIV and AIDS. Only 9.3\% reported attending a raising awareness session about HIV infection. Only $16.7 \%$ reported knowing a person living with HIV and only $5.8 \%$ reported knowing a friend living with or died from HIV infection. Sharing infected needles, vertical transmission and breast milk were recognized as sources for HIV infection by $76.3 \%$. $78.4 \%$ and $64.3 \%$, respectively. However, misconceptions associated with HIV infection such as insect bites and sharing food were reported by $29.7 \%$ and $30.2 \%$ of participants in this study. Having one faithful healthy partner and abstaining from sex were reported as methods for prevention of HIV by $54.8 \%$ each. Proper condom use as a method for prevention of HIV was reported by $40.4 \%$. Apparently healthy persons were recognized as possible source of infection with HIV by $44.8 \%$. Very few participants were willing to share food with a person living with HIV (PLHIV) (18.6\%). A minority accepted to have sex without or with use of condom with PLHIV (1.9\% and $7.4 \%$, respectively). Nearly one third only accepted to take care for a friend living with HIV $(31.3 \%)$, buy grocery from infected person $(26.9 \%)$ or continue meeting a friend living with HIV (33.6\%). More than one half $(57.1 \%)$ knew about confidential counselling and testing services but only $8.4 \%$ ever been tested for HIV. The majority of them (97.2\%) were tested on voluntarily basis and were informed about their test results. Most of those tested performed the test during the last year (86.1\%) (Table 3).

\section{Discussion}

The Egyptian Journal of Community Medicine

$\begin{array}{llll}\text { Vol. } 35 & \text { No. } 4 & \text { October } & 2017\end{array}$ 
Because of high infection rates and large numbers of sexual partners, sex workers were considered a core group for the transmission of HIV and other sexually transmitted diseases. In addition, commercial and non-commercial FSWs play a major role in transmitting HIV and other STIs infections into the general population. These "bridge" populations may be as important as core groups in direct prevention programs. ${ }^{12}$ The majority of participants in the present study were of middle age groups (20-40 years). This middle age group was the most frequently encountered among sex workers, which is considered the age of sexual attractiveness and sexual activity. ${ }^{13,14}$ This age group is most frequently affected by HIV/AIDS and other sexually transmitted infections. ${ }^{13-15} \mathrm{~A}$ study in Morocco showed that $67 \%$ of reported cases of HIV infections were among FSWs, their clients and their steady partners. ${ }^{16}$

In the present study, nearly one-half of participants completed primary education and only, about one-fifth of them completed university education. Education plays a role in occurrence of STIs and is considered a key defense against the spread of STIs. Lower level of STIs/AIDS infection was encountered among better-educated people. Higher education levels were linked with increased STIs/AIDS awareness and knowledge, higher rate of condom use and greater communication on STIs prevention among sexual partners. ${ }^{1}$

The majority of participants in the present study were ever or currently married during the study period. This observation is similar to what was observed in similar studied in Middle East region. ${ }^{17}$ Different studies among FSWs showed that in spite of marital status the majority of them and their husbands were having extramarital temporary or permanent sexual relationships. This unpaid sexual relations act as bridges for transmission of sexual diseases infection from FSWs to other sectors of the community. ${ }^{14-16}$ In the present study, living accommodation was mainly with families. The strong social relations of Egyptian families could explain this. In contrary to western countries, the tendency of adults to live separately from their families is not common in Egypt. In the present study, more than one half of participants were having other jobs and are not working exclusively as sex workers. In conservative countries like Egypt, FSWs tend to have another job as a safe cover against the high social stigma against sex working. ${ }^{18,19}$

As regard risk factors, which influence the occurrence of STIs/AIDS, less than one-half of participants in the present study reported alcohol intake and drug abuse. Addiction status played a role in the occurrence of STIs. UNAIDS reported a high rate of STIs including AIDS among drug abusers (35-80\%). In addition, drug injection has an intimate relation with occurrence of HIV infection. Drug addicts may also have multiple sexual partners. ${ }^{1}$ However, in another study, in Mexico, risk factors associated with probability of sexually transmitted infections were, lack of condom use, years of commercial sex work and illiteracy. ${ }^{20}$

The majority of our participants were knowledgeable about STIs with different level of knowledge about manifestations among males and females. Different studies showed different knowledge of FSWs concerning STIs. A study among street sex workers in Eastern Europe showed that almost all the street sex workers were aware of AIDS but far less 
of other STIs. ${ }^{21}$ The increased exposure to various media including electronic media, people have fair to good knowledge about mode of transmission and manifestations of STIs. ${ }^{22}$ The majority of our participants were able to recognize STIs manifestations among male partners and the main reported action taken was refusing sex practice with men showing manifestations of sexually transmitted infections. One the other hand, participants in the present study reported high incidents of having manifestations suggestive for sexually transmitted infections among them including abnormal vaginal discharge and genital ulcers. It seems that their claims of refraining from sex if the client was infected may not be true. In the present study many sex workers did not abstained from sex and did not inform their partners. It seems logical that women in the sex industry would be unlikely to readily identify abstinence as an important prevention activity, as commercial sex is their primary or the only source of income.

The vast majority of our participants reported starting to seek treatment for STIs manifestations few days or within two weeks of appearance. However, this information is self-reported and cannot be validated. It also contradicted with the observation in the present study of high percentage of participants reporting ever having manifestations suggestive for genital tract infections last year. Preferring of private sector for treatment observed in the present study may be attributed to more confidentiality, privacy at private sector or fear of stigma. This agreed with the study of Mohebbi, 2006, which reported that, FSWs sought treatment for STIs through self-treatment or through friends rather than through knowledgeable health personnel. ${ }^{23}$ Sex workers in Middle East and North Africa continue to suffer from unavailability of medical and support services and continue to fear pursuing such services due to social stigmatization, marginalization, and law enforcement. ${ }^{9,17}$

Although condom is being promoted as a major protection against transmission of STIs/AIDS, only $8.6 \%$ of FSWs participating in the present study used condom to prevent transmission of STIs. A baseline survey among sex workers in Cross River State in Nigeria showed that $11 \%$ only of sex workers always used condoms. ${ }^{24} \mathrm{~A}$ study among Indonesian sex workers showed that condom use was related to knowledge and work location. ${ }^{25}$ Elevated knowledge and working in higher economic levels were associated with higher condom use. Condom use was significantly associated with beliefs about condom ability to prevent STIs/AIDS, pregnancy, enhancing sexual pleasure and selfefficacy. ${ }^{25}$ A study in Egypt showed that More than two-thirds of the sample $(69.6 \%)$ reported availability of condoms in their neighborhood. However, 53.1\% reported that they would be embarrassed to buy condoms. ${ }^{27}$ In the present study, the majority of sex workers heard about AIDS and its modes of transmission. However, some misconceptions were observed. There is a high level of misinformation and many misconceptions about HIV/AIDS in Middle East and North Africa (MENA). ${ }^{9}$ The present study showed that the majority of the participants had correct knowledge about means to avoid HIV/AIDS. Similar findings were also reported in a study on sex workers in Mangolia $^{28}$ and Nigeria. ${ }^{26}$

Concerning, attitude towards people living with HIV, most of our participants 
had negative attitude and refused to deal with them. It seems that the negative attitude of studied FSWs towards people living with HIV is reflection of the prevailing negative attitude among the general population in the community they live. ${ }^{17}$ The attitude towards infected person with HIV also depends largely on the social acceptability of mode of transmission a person get infected. ${ }^{30}$

A slightly more than half $(57.1 \%)$ of our participants knew about confidential counseling and testing. However, few of them ever had HIV testing in the last year. This may be attributed to lack of knowledge about importance of early testing. HIV Testing is influenced by complex interplay of personal risk perception, social relationship and community disclosure. In addition, HIV treatment and testing may be hampered by high cost of treatment, judgmental attitude of service providers and lack of information on testing services. ${ }^{30}$ However a study in Netherlands revealed that, $82 \%$ of all commercial sex workers reported a prior HIV test and $2 \%$ of them were positive. ${ }^{5}$

Limitations: the present study was not able to include sex workers of two of the identified categories due to budget limits and safety issues. The practices in the present study ere self reported. The researchers cannot ensure validity of self-reported data.

Acknowledgment:The authors want to thank all females who participated in this study and those who helped by referring us to others, especially Al-Shehab, a non-government organization working in same field.

\section{References}

1. UNAIDS: AIDS scorecards overview: UNAIDS report on the global AIDS epidemic. UNAIDS, 2013, avaialble at: http://www.unaids.org/sites/default/files/ en/media/unaids/contentassets/document s/epidemiology/2013/gr2013/UNAIDS Global_Report_2013_en.pdf

2. World Health Organization: HIV/AIDS sex work toolkit. WHO, 2012. Available at: http://www.who.int/hiv/topics/vct/sw_to olkit/en/

3. UNAIDS: UNAIDS Guidance Note on HIV and Sex Work. UNAIDS 2012. Available at: http://www.unaids.org/en/ resources/documents/2012/20120402_U NAIDS-guidance-note-HIV-sex-work

4. Taylor-Gooby P and Zinn JO: Current directions in risk research: new developments in psychology and sociology. Risk Anal 2006,26:397-411

5. Van veen MG, Gotz HM, Van Leeuwen PA, Prins $M$ and Van de Lar MJ: HIV and Sexual Risk Behavior among Commercial Sex Workers in the Netherlands. Arch Sex Beha. 2010, 39 (3):714-723.

6. Macmanus A and Dhar L : Study of knowledge, perception and attitude of adolescent girls towards STIs/HIV safer sex and sex education: (A cross sectional survey of urban adolescents school girls in south Delhi, India).BMC Women Health 2008,8:12

7. UNFPA: Sexually Transmitted Infection: Breaking the cycle of transmission. 2004. Available at: http://www.unfpa.org/rh/stis.htm.

8. UNAIDS: Global report: UNAIDS Report on the Global AIDS Epidemic, 2010. "UNAIDS/10.11E | JC1958E"

9. Abu-Raddad LJ, Hilmi N, Mumtaz G, Benkirane M, Akala FA, Riedner G, Tawil O, Wilson D: Epidemiology of HIV infection in the Middle East and North Africa. AIDS. 2010, 24(suppl.,2):S5-23.

10. Central Agency for Public Mobilization and Statistics: Statistic

Vol. 35

No. 4

October

2017 
Tables for Population at Governorate Level, CAPMAS 2006. Available at: www.capmas.gov.eg/statistics/populatio $\underline{\mathrm{n} / \text { final results of population and housing }}$ census.

11. Amon J, Brown $T$, Hogle $J$, MacNeil J, Magnani R, Mills S, Pisani E., Rehle T, Saidle T, and Sow C .: Behavioral Surveillance Surveys: Guideline for repeated behavioral surveys in populations at risk for HIV. Family Health International, 2000, pp210-230.

12. Morris M, Podhisita C, Wawer MJ and Handcock MS : Bridge populations in the spread of HIV/AIDS in Thailand. AIDS 1996,10:1265-1271.

13. Sajadi L, Mirzazadeh A, Navadeh S, Osooli M, Khajehkazemi R, Gouya M, Fahimfar N, Zamani O, and Hagdoost A.: HIV prevalence and related risk behaviours among female sex workers in Iran: results of the national biobehaviorural survey, 2010.Sex Transm Infect. 2013, 89:iii37-iii40.

14. Elhadi M, Elbadwai A, Abdelrahman S, Mohammaed I, Bozicevic I, Hassan E, Ahmed S, Sidahmad M, Mubarak N, Elsanousi S and Setayesh H.: Integrated biobehavioural HIV surveillance surveys among female sex workers in Sudan, 2011-2012. Sex Transm Infect. 2013, 89:iii17-iii22

15. National HIV/AIDS Control Program: National HIV/AIDS control program Statistics. Ministry of Health and Population, Egypt. 2004.

16. Mumtaz G, Kouyomumijian S, Hilmi H, Zidouh A, Rhilani H, Alami K, Bennani A, Gouws E, Ghys P, and AbuRaddad L. : The distribution of new HIV infections by mode of exposure in Morocco. Sex Transm Infect. 2013, 0:18.
17. Abu-Raddad, L, Ghanem K, Feizzadeh A, Setayesh H, Calleja JMC, and Riedner G. : HIV and other sexually transmitted infections research in the Middle east and North Africa: promising progress?. Sex Transm Infect.2013, 89 (S3) :iii1-iii4.

18. Kabbash IA, Abdul-Rahman I, Shehata Y and Omar A.: HIV infection and related risk behaviours among female sex workers in greater Cairo, Egypt. EMHJ.2012, 18 (9):920-27.

19. Kabbash IA, Abdul-Rahman I, and Shehata Y.: Looking beyond legality: understanding the context of female sex workers in greater Cairo, Egypt. EMHJ.2013, 19 (1):24-29.

20. Reyes M C B, Rivera LP, Valdez $\mathrm{AC}$ and Giron CAH: Prevalence of sexually transmitted infections and associated risk factors among female commercial sex workers in Cuautla, Morelos. Grinecol Obstet Mex.2005, 73(1):36-47. (English abstract)

21. Veller Fornasa C, Gai F, Tarantello M, and Gallina P.: Knowledge of sexually transmitted diseases and condom use among female street sex workers in Padua. Acta Dermatoven APA. 2005, 14 (3):107-110.

22. Egger $\mathrm{m}$, Ferri J, Gorter $\mathrm{A}$ and Gonzalez S (2003): HIV/AIDS related knowledge, attitude and practice among Monaguan sex workers Bull Pan Am Health Organ 2003, 27:360-9

23. Mohebbi R : Female Sex Workers and Fear of Stigmatization. Sex Trans. Infect. 2006, 81:2 180-181

24. Eka Esu-Williams: Sexually transmitted diseases and condom interventions among prostitutes and their clients in Cross River State, Nigeria. Health Transition Review, Supplement to Volume 5, 1995, 223-228.

25. Ford K, Wirawan DN and Faijans $\mathrm{P}$ : Factors related to condom use among 
four groups of female sex workers in Bali, Indonesia. AIDS Educ Prev. 1998, 10(1):34-45.

26. Umar US, Adekunle AO and Bakare

RA : Pattern of condom use among commercial sex workers in Ibadan, Nigeria. Afr J Med Sci. 2001, 30(4):35890.

27. Kabbash IA, El-Sayed NM, AlNawawy AN, Shady IK, and Abou Zeid MS.: Condom use among males (15-49 years) in Lower Egypt: knowledge, attitudes and patterns of use. EMHJ.2007, 13(6):1405-16.

28. Enkhbold S, Lugsdelger S, Morita S, Sakamoto $\mathrm{J}$ and Hamajima $\mathrm{N}$ : HIV/AIDS related Knowledge and Risk Behaviors among female sex workers in two major cities of Mangolia. Nagoya J Med Sci. 2007, 69 (3-4):157-165.

29. Badahdah A : Saudi attitudes towards people living with HIV/AIDS. Int J STD AIDS. 2005 16:837-838

30. Ngo A D, Latifff E A and McCurdy $S$ A: Health seeking behavior for sexually transmitted infections And HIV testing among female sex workers in Vietnam. AIDS Care. 2007, 19(7): 878887.

This research received funding from the National HIV/AIDS Control Program, Ministry of Health \& Population, Cairo, Egypt.

The authors declare no conflict of interest of any kind. 
Table (1): Sociodemographic characteristics of the studied female sex workers

\begin{tabular}{|l|r|r|}
\hline Characteristic & No. $(\mathbf{n}=\mathbf{4 3 1})$ & \multicolumn{1}{|c|}{$\%$} \\
\hline Age (years) & & \\
<20 & 44 & 10.2 \\
$20-$ & 183 & 42.5 \\
$30-$ & 98 & 22.7 \\
$40-$ & 51 & 11.8 \\
$50-$ & 18 & 4.2 \\
Unrecorded & 37 & 8.6 \\
\hline Education & & \\
Attended school & 262 & 60.8 \\
Duration of education $(n=262)$ & & \\
$\quad$ Primary (1-9 years) & 129 & 49.2 \\
$\quad$ Secondary (10-12 years) & 83 & 31.7 \\
$\quad$ University & 50 & 19.1 \\
\hline Ever married & & 65.9 \\
\hline Living with: & & \\
Husband & 158 & 36.7 \\
Male sexual partner & 20 & 4.6 \\
Female sexual partner & 2 & 0.5 \\
A friend & 25 & 5.8 \\
Family & 178 & 41.3 \\
Alone & 42 & 9.7 \\
Unrecorded & 6 & 1.0 \\
\hline Having other job as a source of income & & \\
No & 172 & 39.9 \\
Yes & 232 & 53.8 \\
Unrecorded & 27 & 6.3 \\
\hline Drug use last month & 211 & 49.0 \\
\hline Inject drug last moth & 24 & 5.6 \\
\hline Drug intake is associated with sex & 162 & 37.6 \\
\hline Alcohol intake: & & \\
Daily & 30 & 7.0 \\
At least once weekly & 70 & 16.2 \\
2-3 times/month & 72 & 16.7 \\
None & 259 & 60.1 \\
\hline Drug use: & & \\
Used drugs & 211 & 49.0 \\
Injecting drugs last year & 5.6 \\
Use of drugs associated with sex & 162 & 37.6 \\
\hline & & \\
\hline
\end{tabular}


Table (2): Distribution of participants according to their knowledge and practice towards sexually transmitted infections

\begin{tabular}{|c|c|c|}
\hline \multirow{2}{*}{\multicolumn{3}{|c|}{$\begin{array}{l}\text { Variables } \\
\text { Knowino ceyally transmitted infections(STIs). }\end{array}$}} \\
\hline & & \\
\hline Yes & 333 & 77.3 \\
\hline No & 86 & 20.0 \\
\hline No answer & 12 & 2.8 \\
\hline Manifestations of STIs among women: & & \\
\hline Abdominal pain & 79 & 18.3 \\
\hline Unusual vaginal discharge & 327 & 75.9 \\
\hline Bad odour vaginal discharge & 358 & 83.1 \\
\hline Burning sensation during urination & 178 & 41.3 \\
\hline Genital ulcers & 194 & 45.0 \\
\hline Genital itching & 309 & 71.7 \\
\hline Inguinal swelling & 83 & 19.3 \\
\hline No answer & 10 & 2.3 \\
\hline Manifestations of STIs among men: & & \\
\hline Urethral discharge & 320 & 74.2 \\
\hline Burning sensation during urination & 208 & 48.3 \\
\hline Genital ulcers & 197 & 45.7 \\
\hline Genital itching & 272 & 63.1 \\
\hline Inguinal swelling & 81 & 18.8 \\
\hline No answer & 21 & 4.9 \\
\hline Actions taken for observed STIs manifestations in clients : & & \\
\hline Refuse sex & 303 & 70.3 \\
\hline Use condom & 37 & 8.6 \\
\hline Practice sex without condom & 75 & 17.4 \\
\hline No answer & 16 & 3.7 \\
\hline Ever suffer from unusual vaginal discharge last year & 328 & 76.1 \\
\hline Ever suffer from genital ulcers last year & 67 & 15.5 \\
\hline Actions when observing self STIs manifestations : & & \\
\hline Inform my sexual partner & 173 & 40.1 \\
\hline Never inform my sexual partner & 183 & 42.5 \\
\hline Stop working till clearance of manifestations & 73 & 16.9 \\
\hline Stop working till taking appropriate treatment & 152 & 35.3 \\
\hline Continue working while using condom & 27 & 6.3 \\
\hline Continue working without using condom & 60 & 13.9 \\
\hline Duration to start treatment for STIs: & & \\
\hline Few days & 272 & 63.1 \\
\hline $1-2$ weeks & 70 & 16.2 \\
\hline 2-4 weeks & 11 & 2.6 \\
\hline A month or more & 12 & 2.8 \\
\hline Never interested in treatment & 64 & 14.8 \\
\hline No answer & 2 & 0.5 \\
\hline Preferred source of treatment for STIs: & & \\
\hline Governmental hospital & 145 & 33.6 \\
\hline Private clinics /hospitals & 198 & 45.9 \\
\hline Pharmacies & 90 & 20.9 \\
\hline Friends & 34 & 7.9 \\
\hline Herbal and traditional therapy & 52 & 12.1 \\
\hline
\end{tabular}

\begin{tabular}{lllll}
\hline The Egyptian Journal of Community Medicine & Vol. 35 & No. 4 & October & 2017
\end{tabular}


Table (3): Distribution of studied according to their knowledge, attitude and practices about HIV/AIDS

\begin{tabular}{|c|c|c|}
\hline Variables & No. $(n=431)$ & $\%$ \\
\hline Ever heard about HIV/AIDS & 400 & 92.8 \\
\hline Ever sharing in raising awareness about HIV/AIDS & 40 & 9.3 \\
\hline Knowing a person living with or died from HIV & 72 & 16.7 \\
\hline Having a friend living with or died from HIV & 25 & 5.8 \\
\hline Transmission of HIV infection: & & \\
\hline Insect bites & 128 & 29.7 \\
\hline Sharing food & 130 & 30.2 \\
\hline Sharing needles & 329 & 76.3 \\
\hline From pregnant women to her baby & 338 & 78.4 \\
\hline By breast milk & 277 & 64.3 \\
\hline Prevention of HIV infection: & & \\
\hline Proper condom use prevented HIV infection & 174 & 40.4 \\
\hline Having one faithful healthy partner & 220 & 54.8 \\
\hline Abstain from sex & 236 & 54.8 \\
\hline Attitude towards people living with HIV(PLHIV): & & \\
\hline Apparently healthy person can transmit infection & 193 & 44.8 \\
\hline Accept sharing food with PLHIV & 80 & 18.6 \\
\hline Accept sex with infected friend without condom & 8 & 1.9 \\
\hline Accept sex with infected friend with condom use & 32 & 7.4 \\
\hline Accept taking care for a friend living with HIV & 135 & 31.3 \\
\hline Accept buying grocery from PLHIV & 116 & 26.9 \\
\hline Accept meeting \& dealing with friends living with HIV & 145 & 33.6 \\
\hline $\begin{array}{lllll}\begin{array}{l}\text { Knowing about } \\
\text { testing( } \mathrm{n}=431)\end{array} & \text { HIV } & \text { confidential } & \text { counselling } & \text { \& } \\
\end{array}$ & 246 & 57.1 \\
\hline Ever had HIV testing $(\mathrm{n}=431)$ & 36 & 8.4 \\
\hline Voluntary HIV testing $(n=36)$ & 35 & 97.2 \\
\hline Informed about test results $(\mathrm{n}=36)$ & 35 & 97.2 \\
\hline Last time performing HIV testing: $(n=36)$ & & \\
\hline During last year & 31 & 86.1 \\
\hline $1-2$ year ago & 2 & 5.5 \\
\hline $2-4$ years ago & 1 & 2.8 \\
\hline More than 4 years ago & 1 & 2.8 \\
\hline Don’t know & 1 & 2.8 \\
\hline
\end{tabular}

